\title{
Resenha Os Conceitos Jurídicos Fundamentais Aplicados na Argumentação Judicial
}

\author{
Luiz Gonzaga Silva Adolfo ${ }^{1}$ \\ Véra Lucia Cavichioli Barbosa ${ }^{2}$ \\ Rafaela Silva Melo Silva ${ }^{3}$
}

Formado na Harvard, em 1904, Wesley Newcomb Hohfeld deixou um dos mais valiosos e influentes contributos para a teoria analítica do Direito do século XX, publicado, em título póstumo, no ano de 1949. Na sequência, uma breve explanação sobre pontos principais da obra aqui em exame.

\section{Primeira Parte}

Encarando o árduo trabalho de enfrentar a nebulosidade da terminologia jurídica reinante, e analisando a vasta gama de exemplos do uso dos conceitos empregados, não apenas na jurisprudência, na doutrina e, princi-

1 Doutor em Direito pela UNISINOS (São Leopoldo/RS). Presidente da Comissão Especial de Propriedade Intelectual da OAB/RS na gestão 2010/2012. Membro da Associação Portuguesa de Direito Intelectual - APDI. Professor do PPG em Direito da Universidade de Santa Cruz do Sul - UNISC. Professor dos Cursos de Direito da Universidade Luterana do Brasil - ULBRA (Gravataí/RS) e do Instituto Brasileiro de Gestão de Negócios - IBGEN (Porto Alegre/RS). Advogado. E-mail: gonzagaadolfo@ yahoo.com.br.

2 Acadêmica do Curso de Direito da Ulbra Gravataí. E-mail: veralcb@gmail.com.

3 Acadêmica do Curso de Direito da Ulbra Gravataí. E-mail: rsraphamel@gmail.com.

Recebido em: 27/03/2012.

Revisado em: 11/04/2012.

Aprovado em: 15/04/2012. 
palmente, na produção contemporânea, o autor alicerça o peso de sua obra na precisão com que esquadrinha as relações jurídicas entre sujeitos de direito. Ele se preocupa sobremaneira com a seleção lexical e torna rigorosamente preciso o verdadeiro sentido de cada um dos vocábulos que utiliza para expressar suas ideias, identificando e classificando os vários elementos de que se compõem.

$\mathrm{Na}$ obra, os conceitos jurídicos fundamentais aplicados na argumentação jurídica, o principal foco do autor é o de salientar certas matérias, que são frequentemente negligenciadas e que poderão auxiliar a compreensão e a resolução de problemas práticos e quotidianos do direito. Com esse objetivo, o autor discute, preocupadamente, os conceitos básicos do direito - os elementos jurídicos presentes em todo o tipo de interesses a ele concernentes.

Nas primeiras seções, sob os títulos Conceitos Jurídicos em contraste com conceitos não jurídicos, Fatos operativos contrastados com fatos probatórios e As relações jurídicas fundamentais contrastadas entre si, salienta-se que aqueles que se dedicam ao direito precisam dominá-lo por meio de uma visão crítica e, com esta, obter uma noção rigorosa do que é entendido por direito objetivo, direito subjetivo, dever, dolo, intenção, negligência, proporcionalidade, posse e, assim, sucessivamente, pois, não poucas vezes, os mais altos tribunais parecem ter tropeçado em razão de não terem ideias límpidas sobre alguns destes temas, pela terminologia solta e ambígua. A contribuição de Wesley Newcomb Hohfeld para o direito probatório é, precisamente, a sua constante insistência na necessidade de clarificação da nossa terminologia jurídica e a elaboração de cuidadosas "distinções" entre conceitos e termos que são constantemente tratados como se fossem a mesma coisa, pois "[...] é um dos infortúnios do direito que as idéias se cristalizem em expressões, e daí em diante, por muito tempo, deixem de originar mais análise." (HOHFELD, 2008, p. 90). Embora todo estudante de lógica saiba, raramente ele se dá conta do poder e da influência desencadeada pelo uso das palavras na elaboração do pensamento e da forma como direcionam/afetam o resultado da controvérsia.

Se tais questões continuarem sendo debatidas tão artificialmente, afigura-se o sério risco de ser-se induzido, por definição técnica, à aplicação de certo nome e, posteriormente, deduzirem-se consequências sem qual- 
quer relação com os fundamentos pelos quais o nome foi aplicado. Como exemplo, temos a palavra "direito", definida por lexicógrafos como denotando, entre outras coisas, propriedade, interesse, poder, prerrogativa, imunidade ou privilégio, embora, em direito como ciência, seja usada, genérica e indiscriminadamente, denotando toda e qualquer vantagem jurídica, quer seja ela uma pretensão, um privilégio, um poder ou uma imunidade, daí confundindo-se, ainda mais, conceitos jurídicos e não jurídicos, conforme o contexto em que são usados.

Portanto, à medida que o nosso direito evolui, confirma-se, cada vez mais premente, dar uma definição à sua fraseologia, uma vez que não só se multiplicam as distinções como também despontam novas situações e problemas delas decorrentes que obrigam a revisão das antigas roupagens das ideias, fazendo com que as diferenciações e expressões tenham de ser, cuidadosamente, revistas.

O direito não difere tanto das outras matérias da análise humana que a cristalinidade do pensamento não nos leve, necessariamente, a seu aprendizado. Logo, se os termos de uso jurídico comum forem empregados da forma adequada, será imprescindível sabê-los e, se, ao contrário, forem tomados de forma inadequada, também será importante conhecê-los, verificando, exatamente, o que, cada um, representa no mundo jurídico. Com essa constatação em mente, o autor considera, ainda, que

[...] a grande importância prática do pensamento rigoroso e da expressão exata no que respeita às idéias jurídicas básicas e à sua incorporação numa terminologia não calculada para induzir em erro, nem sempre é completamente assimilada - especialmente pelo estudante, ainda não muito avançado no seu trabalho jurídico. (HOHFELD, 2008, p. 88)

Paralelamente, também é

[...] verdade que muitos juristas experientes têm presumido, demasiado irrefletidamente, que aquelas matérias normalmente consideradas em trabalhos da chamada 'teoria do direito' (jurisprudence) têm uma natureza meramente 'acadêmica' e são desprovidas de utilidade substancial para o advogado ou para o juiz. (HOHFELD, 2008, p. 88) 
Entretanto, quando alguém se dedica ao direito, precisa ter uma noção inflexível do que se entende por direito objetivo, direito subjetivo, dever, dolo, intenção, negligência, propriedade, posse e, assim, sucessivamente, pois não são raras as ocasiões em que os mais altos tribunais acabam se equivocando em alguns casos por não terem uma conceituação claramente definida sobre cada um desses temas, o que reforça a significativa importância da precisão do pensamento e da expressão exata na exposição das ideias jurídicas.

Em outras palavras, a falta de exatidão nos conceitos leva as situações jurídicas a serem vistas e tratadas como despidas de sua real complexidade, constituindo uma séria barreira ao claro entendimento, à enunciação ordenada e à solução adequada dos problemas jurídicos. Por conseguinte, somente uma análise mais profunda e discriminada poderá levar a uma forma mais simples e correta de interpretação.

Os equivocados argumentos que se ouvem, quase diariamente, em tribunais, assim como um número considerável de pareceres judiciais, oriundos da distorção provocada por uma fraseologia repleta de termos ambíguos, fornecem amplas provas de uma tendência antiga e infeliz que, além de confundir, misturam os elementos jurídicos e não jurídicos num dado problema.

Como explicação para esse fato, Hohfeld diz que há, pelo menos, duas razões. A primeira é a grande proximidade na associação de ideias envolvidas no conjunto das relações físicas e mentais de um lado e as puramente jurídicas do outro, situação essa que apresenta uma acentuada influência tanto nas doutrinas gerais quanto nas regras específicas dos sistemas jurídicos antigos. A segunda razão é a ambiguidade e a fluidez da nossa terminologia jurídica resultante da tendência de misturar os conceitos jurídicos e não jurídicos. A palavra "propriedade" fornece um exemplo marcante, uma vez que não tem uma conotação claramente definida nem entre juristas nem entre leigos, tanto que, por ser usada num sentido tão "misturado", termina por não transmitir um significado definido de sorte que já não especifica somente terras e edifícios, mas, também, tudo o que possa ser recebido como herança, seja corpóreo ou incorpóreo, real, pessoal ou misto. 
Reconhecendo-se o amplo e indiscriminado uso do termo "direito", indaga-se qual é o vestígio balizador que se pode encontrar no discurso jurídico normal e que nos licencia a restringir a palavra em causa a um significado definido e apropriado. Esse balizador pode ser encontrado no correlativo "dever", se observarmos que, até mesmo, aqueles que usam a palavra e a concepção "direito" da forma mais abrangente possível, usualmente, pensam em "dever" como o seu invariável correlativo.

Hohfeld, considerando que um privilégio é o oposto de um dever e o correlativo de um "não direito", mostra "[...] que o privilégio de entrar, por exemplo, é a negação de um dever de não entrar e um dever é o correlativo invariável daquela relação jurídica que mais propriamente se chama direito ou pretensão". Partindo dessa ponderação, fica explícita a importância e a necessidade de manter distintos um do outro o conceito de direito (ou pretensão) e o conceito de privilégio, como implícita, também, é a veemente exigência de existir uma palavra própria para representar, claramente, esses dois termos. O uso comum e indiscriminado de tais termos leva a uma confusão ou desfocagem de ideias.

No decorrer da obra, Hohfeld (2008), a exemplo do que foi mencionado anteriormente, analisa outros conceitos jurídicos, comparando-os com algum detalhe, objetivando mostrar não só o seu significado intrínseco e escopo como também seu interrelacionamento e os métodos pelos quais são aplicados na argumentação judicial à solução de problemas concretos de litigância: direitos e deveres, privilégios e não direitos, poderes e sujeições, imunidade e impotências - parecem ser o que poderá chamar-se "[...] os mínimos denominadores comuns do direito."

\section{Segunda Parte}

Na segunda parte da obra que se está resenhando, o autor apresenta, convenientemente, "Conceitos jurídicos em contraste com conceitos não jurídicos", "Fatos operativos contrastados com fatos probatórios" e "As relações jurídicas fundamentais contrastadas entre si” em um conveniente "[...] esquema de opostos e correlativos." (HOHFELD, 2008, p. 89-90). Ressaltando que os conceitos, que ele definiu como "fundamentais" não di- 
zem respeito a toda a Teoria do Direito, mas tão somente aos institutos verificados no modelo teórico tradicional de relação jurídica, entendida como a relação social entre partes de interesse para o comando normativo jurídico, decidindo não impor conceitos predeterminados a partir de uma análise meramente teórica da relação jurídica, observou os usos já utilizados na prática cotidiana dos juristas para realizar o isolamento dos conceitos que, efetivamente, marcavam distinções válidas, redefinindo cada um deles de modo a que apresentassem um sentido único.

Hohfeld (2008) ressalta que, na proporção em que a massa do nosso direito legislativo e jurisprudencial vai-se avolumando, paralelamente, cresce a necessidade da importância de classificação correta dos termos jurídicos, não apenas por seu valor intrínseco enquanto ferramentas de raciocínio para compreensão e sistematização de nossos intrincados materiais jurídicos como também por fazerem parte, hoje mais do que em qualquer outro tempo, da base formal da argumentação e decisão judiciais.

Como mais um exemplo, cita as expressões in personam e in rem, comumente consideradas por inúmeros juízes, autores e advogados como tendo um significado invariável, portanto livre de ambiguidades indutoras a erros. A situação de tais expressões é exatamente a oposta, como observado pelos juízes com seus avisos merecedores de atenção, uma vez que os incautos são por elas conduzidos a erros pelo seu uso abusivo.

Os conceitos fundamentais de Hohfeld (2008) passam a ser definidos. No que se refere ao Direito em sentido estrito, trata-se da faculdade de exigir uma prestação, uma conduta, por parte do sujeito passivo em relação ao outro polo da conexão jurídica.

Por sua vez, o Privilégio é a possibilidade de praticar um ato ou de inserir-se em uma situação jurídica mediante uma conduta por parte do polo ativo, o titular do privilégio, cujos efeitos recaem sobre o próprio sujeito ativo.

Já o Poder é a capacidade de produzir determinados efeitos jurídicos em relação ao polo passivo. Por meio dessa faculdade, o titular do direito promove efeitos sobre outro sujeito, inserindo-o em uma situação jurídica, ainda que contra sua vontade. E a Imunidade é o atributo jurídico que per- 
mite ao seu titular não ser afetado pelos efeitos jurídicos do ato de determinado sujeito. $\mathrm{O}$ polo ativo tem imunidade em relação ao polo passivo: se os atos deste não forem aptos a produzir efeitos sobre aquele, ter poder sobre o outro não significa estar imune em relação a ele.

O Dever, em sentido estrito, é a situação jurídica de quem está obrigado a uma prestação em relação a outrem: o polo passivo (devedor) é obrigado a realizar uma prestação ao polo ativo. E o Não direito vem a ser uma situação que se contrapõe como correlata ao privilégio, na qual o titular do privilégio tem a faculdade de praticar um ato; o polo passivo dessa relação tem o não direito de impedir que o polo ativo realize a conduta objeto do privilégio. É situação oposta ao direito (pretensão).

Por conseguinte, a Sujeição é apresentada como condição de quem será, necessariamente, submetido aos efeitos jurídicos do ato praticado pelo titular de um poder. O poder encerra uma espécie de privilégio, pois o sujeito passivo não pode impedir que o titular exercesse o ato, pois quem está em sujeição tem, também, o "não direito" de impedir que o ato seja realizado e, além de o sujeito passivo não poder impedir a realização do ato por parte do polo ativo, estará, obrigatoriamente, submetido aos efeitos do ato, inserindo-se na situação jurídica dele decorrente, mesmo contra sua vontade. A sujeição é, portanto, situação correlata ao poder e oposta à imunidade.

Por fim, a Incompetência é ausência de qualificação jurídica para a prática de um ato em relação a determinado sujeito, considerado dotado de imunidade em relação ao agente. O praticante do ato é o polo passivo da relação, pois seus efeitos não atingem o destinatário, vez que o agente não é reconhecido pela ordem jurídica como titular de um poder sobre o destinatário. A imunidade é oposta à sujeição, porque "competência é poder". Ser incompetente em relação a outro não significa estar sujeito a esse outro.

\section{Conclusões}

Wesley N. Hohfeld forneceu preciosa contribuição à Teoria do Direito, sendo um preceptor do movimento realista norte-americano, aplicando, contundentemente, nos seus estudos, a pesquisa empírica, marca da metodologia realista que surgiu logo após sua morte, possibilitando, dessa for- 
ma, a definição mais precisa de vocábulos, por vezes, ambíguos e, quase sempre, obscuros em seu conteúdo.

Sua principal sugestão e, também, sua principal preocupação era a de que a terminologia jurídica fosse refinada e tornada mais clara.

Hohfeld foi um teórico analista que observou, detalhadamente, o sistema jurídico de seu país e, com isso, elaborou sua teoria dos conceitos fundamentais do Direito que, como todas as teorias, foi passível de críticas e, certamente, nunca representará a solução dos inúmeros problemas vinculados aos vocábulos jurídicos, embora norteie muitos estudiosos do direito para o caminho a ser trilhado a fim de que melhores teorias jurídico-analíticas surjam dentro do sistema jurídico de cada país, minimizando enormemente os erros de interpretação.

\section{Referência}

HOHFELD, Wesley Newcomb. Os conceitos jurídicos fundamentais aplicados na argumentação judicial. Lisboa: Fundação Calouste Gulbenklan, 2008. 